\title{
Evaluation of central vestibular syndrome in dogs using brainstem auditory evoked responses recorded with surface electrodes
}

\author{
[Avaliação da síndrome vestibular central em cães usando respostas evocadas auditivas do tronco \\ cerebral gravadas com eletrodos de superficie] \\ G.D Stanciu, M. Musteață, M. Armașu, G. Solcan ${ }^{*}$
}

University of Agricultural Sciences and Veterinary Medicine - Iași, Romania

\begin{abstract}
The present study aimed to analyse the wave morphology, amplitude, latency, and intervals of the brainstem auditory evoked responses (BAERs) in dogs with central vestibular syndrome (CVS) recorded with surface electrodes. Ten dogs with CVS were examined by mono- and binaural stimulation, using the Neuropack electrodiagnostic system, with stimulus intensities of 90 dBSPL. BAERs examinations revealed morphological changes of waves I, II, III, and V and decreased amplitudes of all waves in 7/10 dogs. P values obtained were $=0.014$ for wave I amplitude, 0.031 for II, and III and 0.032 for V. Comparing the latencies of waves I, II, III, and V generated by right and left monoaural stimulation in dogs with CVS, we did not observe significant differences $(\mathrm{P}>0.05)$. No statistical differences were observed for BAERs latencies of the waves recorded after binaural and monaural stimulation (left or right). As far as we know, this is the first study of BAERs using surface electrodes, obtained from dogs with CVS.
\end{abstract}

Keywords: dog, brainstem auditory evoked responses, electrophysiology, central vestibular syndrome, surface electrodes

\section{RESUMO}

Este estudo destina-se à análise da morfologia, da amplitude, da latência e do intervalo das ondas das respostas evocadas auditivas no tronco cerebral (BAERs) em cães com síndrome vestibular central (CVS) registrados com eletrodos de superfície. Dez cães com CVS foram examinados por estimulação mono e binaural usando um sistema de eletrodiagnóstico Neuropack, com intensidade do estímulo de 90 dBSPL. Os exames BAERs relevaram alterações morfológicas das ondas I, II, III e V, bem como baixas amplitudes para todas as ondas no caso dos 7/10 cães. Os valores de P obtidos foram $=0.014$ para ampitude da onda I, 0.031 para a II e 0.032 para a V. Compararam-se as latências das ondas I, II, III e V geradas pelo estímulo monoaural direito e esquerdo em cães com CVS e não foram constatadas diferenças significativas $(P>0.05)$. Igualmente não foram observadas diferenças estatísticas no caso das latências BAERs no que diz respeito às ondas gravadas depois de estímulos binaural e monoaural (esquerdo ou direito). Pelo que é de conhecimento dos autores da presente pesquisa, este é o primeiro estudo sobre BAERs usando eletrodos de superfície obtidos em cães com CVS.

Palavras-chave: cão, evocado auditivo de respostas, electrofisiologia, eletrodos de superficie, síndrome vestibular central 


\section{INTRODUCTION}

BAERs is the most used electrophysiological test in veterinary medicine to evaluate the normality of the auditory system (Besalti et al., 2008; Cvejic et al., 2009, Colson et al., 2012). BAERs are the electrical activities generated from the activation of the statoacoustic nerve, cochlear nucleus, tracts and nuclei of the lateral lemniscus and inferior colliculus (Wilson and Mills, 2005). In the first 10 miliseconds (msec) after each stimulus, clinical stimuli delivered to one or both ears evoke up to seven submicrovolt positive waves. The waves are marked in roman numbers from I to VII (Luttgen, 1994; Biacabe et al., 2001; Webb, 2009; Palumbo et al., 2014).

Vestibular diseases (VS) are common in dogs and may result from a lesion in one of the vestibular components (either the peripheral or central) (Steiss et al., 1994; Poma et al, 2008). The clinical signs are represented by head tilt, falling, leaning, rolling, circling, nystagmus, strabismus and ataxia, alone or combined (Wilson and Mills, 2005).

In peracute clinical presentation of vestibular syndrome it is difficult to conclude if the clinical signs are the expression of a lesion in the peripheral or central part of the vestibular system. Those cases are characterized by a severe ataxia associated with inability to walk. On the other hand, in some cases the lesions are characterized by a slow chronic progressive development. In such situations, the patients had no nystagmus and normal proprioception. Also, it is possible to have a peripheral lesion which can develop into a central one.

Usually, the aetiology is different in CVS comparing with the peripheral vestibular syndrome (PVS). PVS is usually associated with otitis media/internal, idiopathic vestibular syndrome, ototoxic drugs and hypothyroidism and CVS with encephalitis, brain tumours, vascular infarctions, and metronidazole toxicity (Wilson and Mills, 2005).

Recording methodology of the BAERs became crucial in establishing which component of the VS is affected. Usually, in veterinary medicine, BAERs are recorded by needle electrodes comparing with human medicine where surface electrodes are preferred. In another study done on animals with CVS, BAERs recorded with needle electrodes showed that there is an increase in central wave latencies comparing with the control (healthy) group (Steiss et al., 1994). Till now there are only few studies performed in animals using surface electrodes (Jost et al., 1994; Musteață et al., 2013). In those studies the wave's morphology was preserved but the latencies were lower than those previously obtained with needle electrodes (Steiss et al., 1994, Cauzinille, 1997).

The goal of this study is to analyse the waves' morphology, amplitudes, latencies and intervals of the BAERs in dogs with CVS recorded with surface electrodes.

\section{MATERIALS AND METHODS}

Ten dogs with CVS were selected for the study. The study was conducted at the Faculty of Veterinary Medicine, Department of Clinical Sciences, Internal Medicine (Neurology), and was performed in accordance with the guidelines and upon approval of the Animal Care Committee of the University of Agricultural Sciences and Veterinary Medicine, Iasi, Romania and Ethical Council of the University (659/01.10.2012). Each dog showed vestibular signs of CVS deficit: falling, torticollis, head tilt, vestibular ataxia, and positional strabismus, alteration of consciousness and proprioceptive sensitivity of the forelimbs. Patients were of mixed breeds, both sexes, aging between three and eleven years.

The diagnosis was made on the basis of anamnesis, clinical appearance, and was confirmed by imagistic examinations (MRI, CT, radiology, and ultrasonography) and BAERs test.

To exclude the systemic conditions (liver and kidney diseases or metastatic neoplasia), in all patients a radiographic evaluation (tympanic bulla and thoracic cavity) and abdominal ultrasonography examination was performed.

Each patient was tested by BAERs. The electrophysiological evaluation was carried out with the Neuropack S, MEB 9400K electrodiagnostic system (Nihon Kohden, Japan) in the auditory brainstem response program (ABR). Examination was done under sedation with medetomidine hydrochloride (Domitor, 
Pfizer, Finland) in a dose of $30 \mu \mathrm{g} / \mathrm{kg}$, inj. i.m. The dogs were positioned in sternal recumbency on a padded table in a sound-attenuated room.

The waves were recorded with circular surface electrodes. The active electrode was placed at the vertex, the negative electrodes just rostral to the opening of the ear canal and the grounding retrooccipitally, on the median line. The area on which the electrodes were placed was trimmed, degreased with Skin Pure NIHON KOHDEN and covered with special adhesive paste (EEG Paste Elefix ${ }^{\circledR}$ NIHON KOHDEN).

Impedance of electrode was kept below $5 \Omega$. Alternating click stimuli of $0.1 \mathrm{~ms}$ were issued by an audio headset type device inserted into the auditory channel. Monaural and binaural stimulation were performed at the intensity of the stimulus of $90 \mathrm{~dB}$ SPL (decibel sound pressure level). Contralateral ear was masked with pure white noise $40 \mathrm{~dB}$ below that of BAERs stimulus. The sound stimulus was 1000 times repeated and averaged (Venker-van Haagen et al., 1989), using a High-cut filter of $100 \mathrm{~Hz}$ and a Low-cut filter of $3000 \mathrm{~Hz}$ (Kawasaki and Inada, 1994; Arnold, 2007). A minimum of 2 series with 1000 stimuli each were averaged for response reproducibility, in order to identify any differences. The average of those two examinations was considered the final value. Artefactual data were automatically rejected; the tests were repeated when rejected waveforms represented more than $5 \%$ of the average.

The results were analysed using the SPSS 20, Wilcoxon Signed Ranks Test for 2 paired samples to determine the presence/absence of statistical differences between the two ears (right and left) or between an ear (right or left) and binaural stimulation. The significance threshold was $\mathrm{P}<0.05$.

\section{RESULTS}

In $7 / 10$ dogs, different types of changes (Tab. 1) in I, II, and III and V waves morphology were observed: multiple discharges in 3 cases (Fig. 1 B), presence of plateau between waves III-V plateau in 3 cases (Fig. 2A), absence of waves II$\mathrm{V}$ (Fig. 2 B) and decreased amplitudes of all waves (Fig. 3). In Fig. 1A a physiological BAERs test is shown.

No significant differences between the two examinations were found $(\mathrm{P}>0.05)$. The values of wave latencies and amplitudes at $90 \mathrm{~dB}$ SPL sound intensities are presented in Tab. 2.

Comparing the latencies of waves I, II, III, and V generated by right and left monoaural stimulation in dogs with CVS, we did not observed significant differences $(\mathrm{P}>0.05)$. No significant differences were observed for BAERs latencies of the waves recorded after binaural and monaural stimulation (left or right).

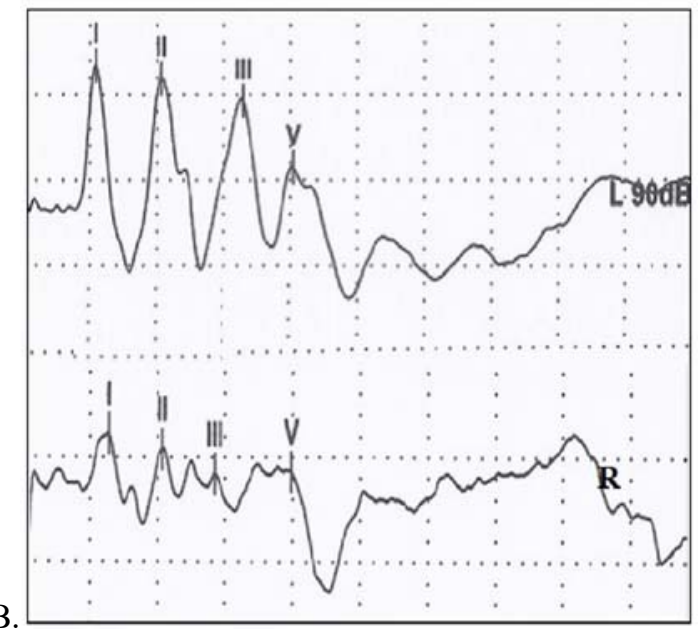

A

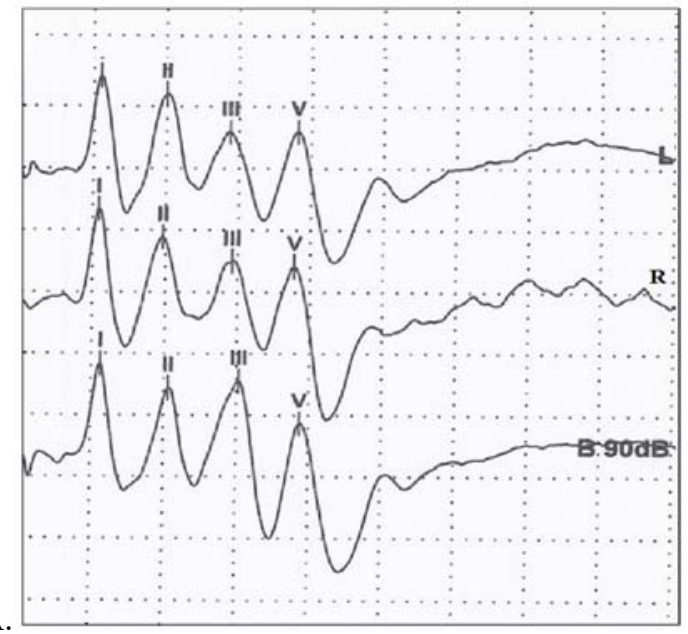

B.

Figure 1. A. A three year old Crossbreed dog without neurological manifestations or hearing deficit. Normal BAERs waves after ear stimulation at an intensity of sound of 90dB SPL. LE = left ear; RE= right ear and B=binaural stimulation; B. Golden Retriever, 11 years old, male. Presence of multiple discharges. 
Evaluation of central...

Table 1. Signalments, clinical signs and final diagnoses in dogs with CVS

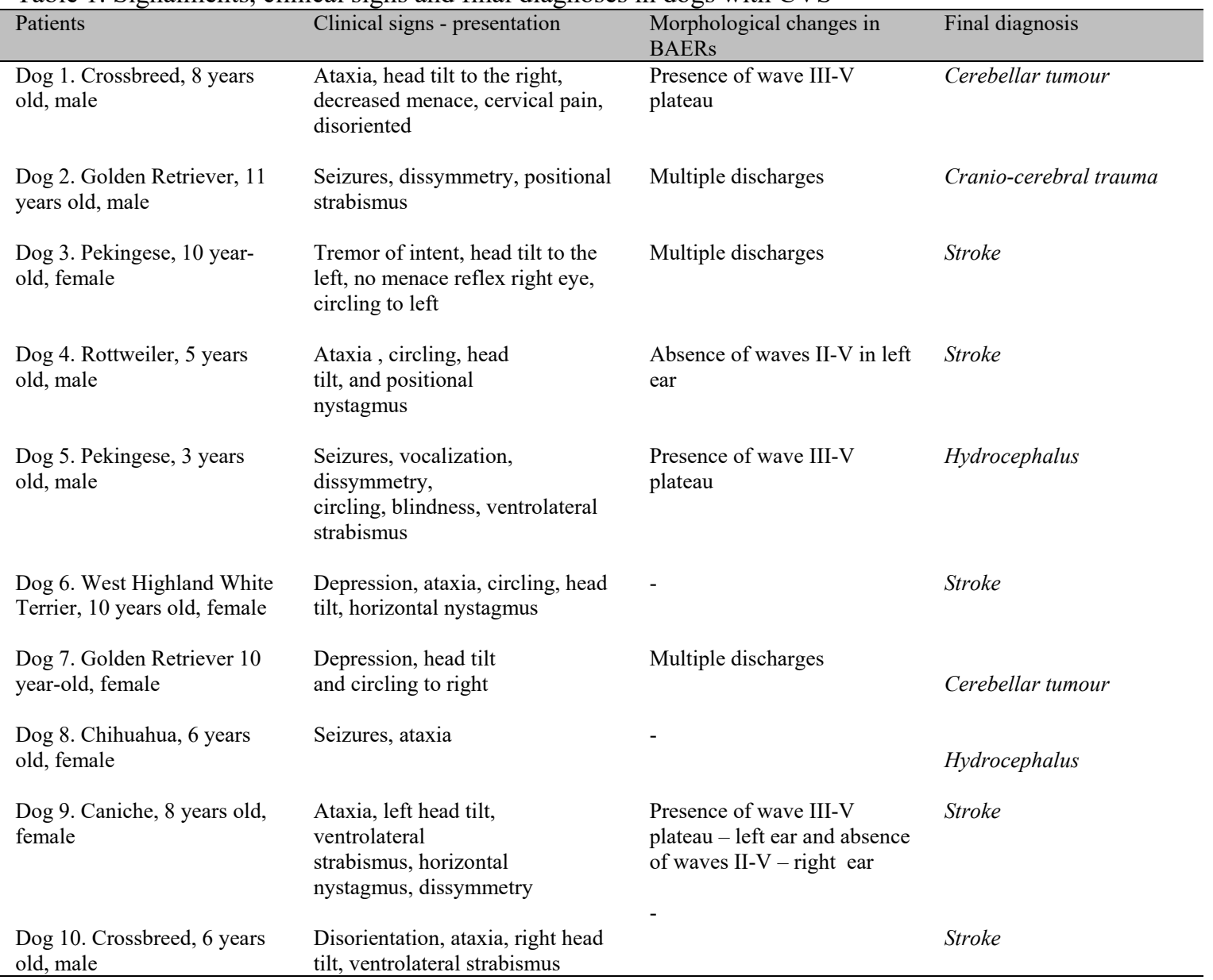
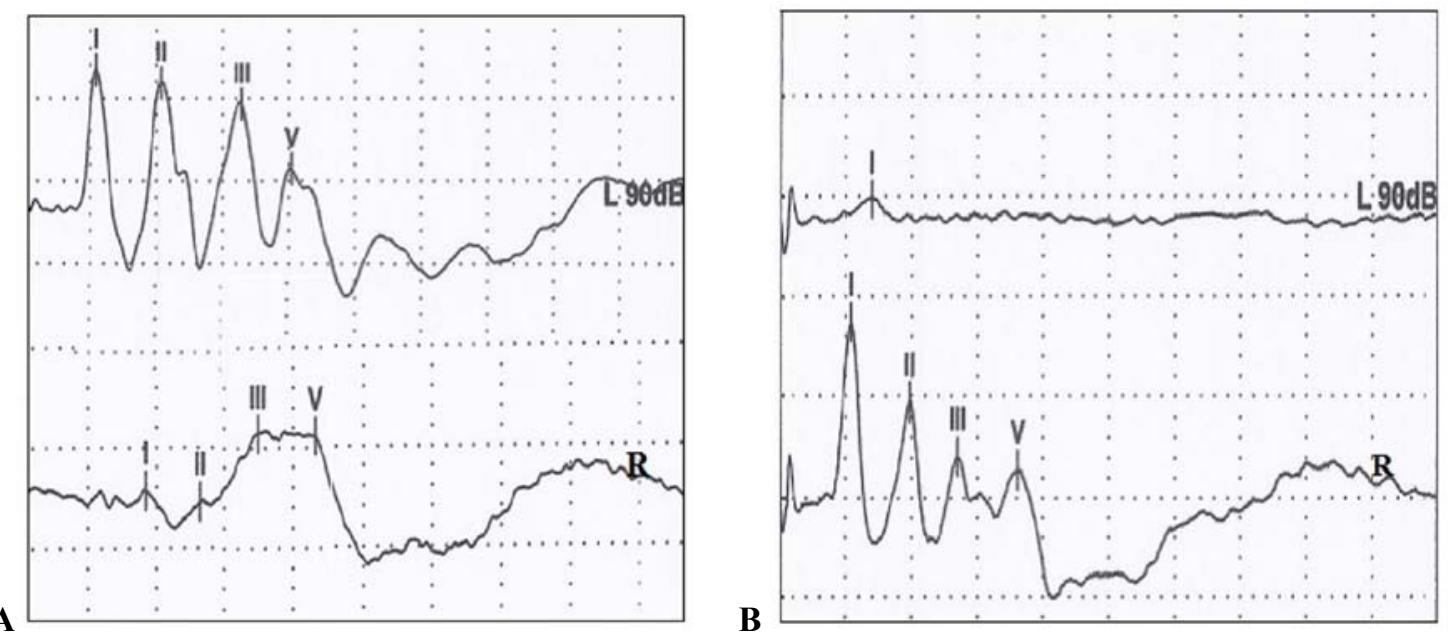

Figure 2. A. BAERs waves for an intensity of sound of $90 \mathrm{~dB}$ in dog with CVS eight year old Caniche female. Presence of a plateau between waves III-V on right ear (RE) stimulation; B. Five year old Rotweiller male. Presence of wave I, a significant decrease in amplitude and dispersion of all centrally generated waveforms, absence of waves II-V on left ear (LE) stimulation and presence of multiple discharges on right ear (RE) and binaural (B) stimulation. 


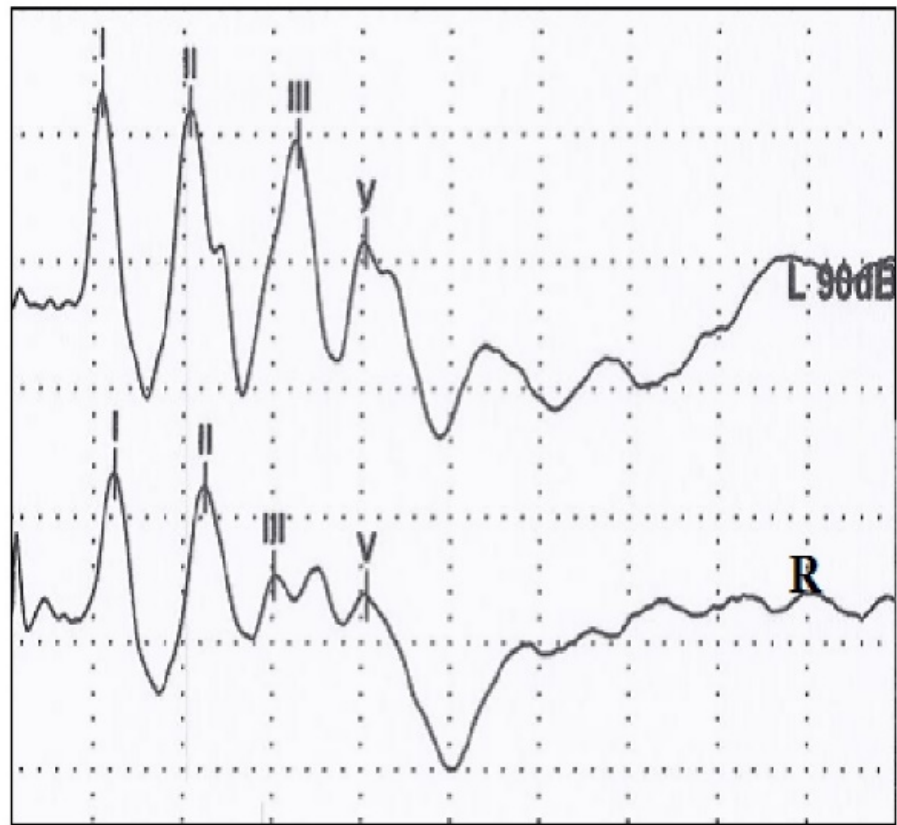

Figure 3. BAERs waves for an intensity of sound of $90 \mathrm{~dB}$ in dogs with central vestibular syndrome. Three year old crossbreed dog. The amplitudes of waves I-V are lower on right ear (RE) stimulation than on the left (LE).

Table 2. Latencies and amplitudes of waves obtained for the ipsilateral ear (with lesion) and the contralateral one (healthy) in dogs with central vestibular syndrome

\begin{tabular}{|c|c|c|c|}
\hline & $\begin{array}{l}\text { Ipsilateral ear (with } \\
\text { lesion) }(\text { mean } \pm \text { SD) }\end{array}$ & $\begin{array}{l}\text { Contralateral ear (normal) } \\
(\text { mean } \pm \mathrm{SD})\end{array}$ & $\mathrm{P}$ \\
\hline \multicolumn{4}{|c|}{ Latencies (ms)/wave } \\
\hline I & $1.09 \pm 0.015$ & $1.11 \pm 0.105$ & $>0.05$ \\
\hline II & $1.97 \pm 0.05$ & $1.97 \pm 0.20$ & $>0.05$ \\
\hline III & $2.93 \pm 0.083$ & $3.01 \pm 0.27$ & $>0.05$ \\
\hline $\mathrm{V}$ & $3.84 \pm 0.020$ & $3.85 \pm 0.40$ & $>0.05$ \\
\hline \multicolumn{4}{|c|}{ Amplitudes $(\mu \mathrm{V}) /$ wave } \\
\hline I & $2.49 \pm 2.18$ & $3.78 \pm 2.19$ & 0.014 \\
\hline II & $2.4 \pm 2.52$ & $3.89 \pm 2.97$ & 0.031 \\
\hline III & $0.61 \pm 1.64$ & $1.96 \pm 1.92$ & 0.032 \\
\hline $\mathrm{V}$ & $1.51 \pm 1.25$ & $2.49 \pm 1.28$ & 0.032 \\
\hline
\end{tabular}

$\mathrm{P} \leq 0.05$ - significant differences, $\mathrm{P} \leq 0.01$ - very significant differences

Comparing the amplitudes of waves I, II, III, and $\mathrm{V}$ recorded after stimulation of the ipsilateral ear (affected) with those recorded after stimulation of the contralateral ear (healthy) significant difference in all waves were observed. In all these situations amplitude of waves from ipsilateral ears was smaller than contralateral (healthy) ones (Fig. 4 A, B and 5A, B). 
A

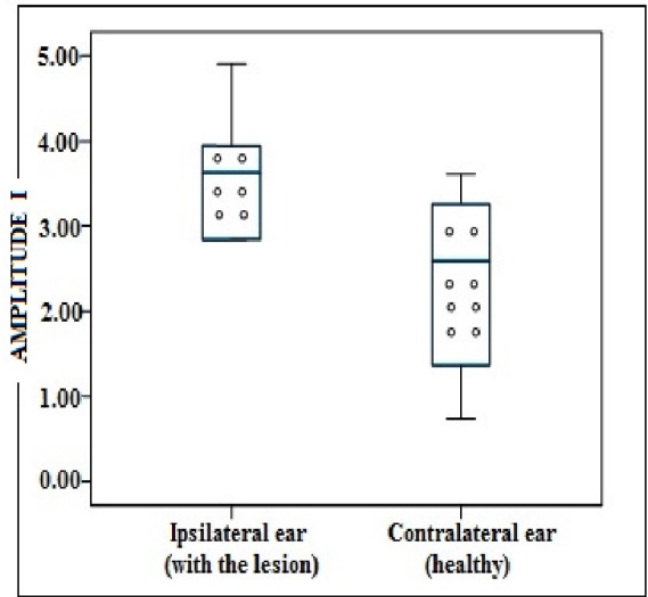

Figure 4. BAERs test performed on dogs with CVS - A. Values of the amplitudes of waves I obtained by stimulation of the contralateral and the ipsilateral ear to the lesion. B. Values for the amplitudes of waves II obtained by stimulation of the contralateral and the ipsilateral ear to the lesion.

No significant differences were observed comparing the values of the amplitudes of waves I, II, III, and $\mathrm{V}$ recorded after binaural and ipsilateral ear (affected) monaural stimulation,

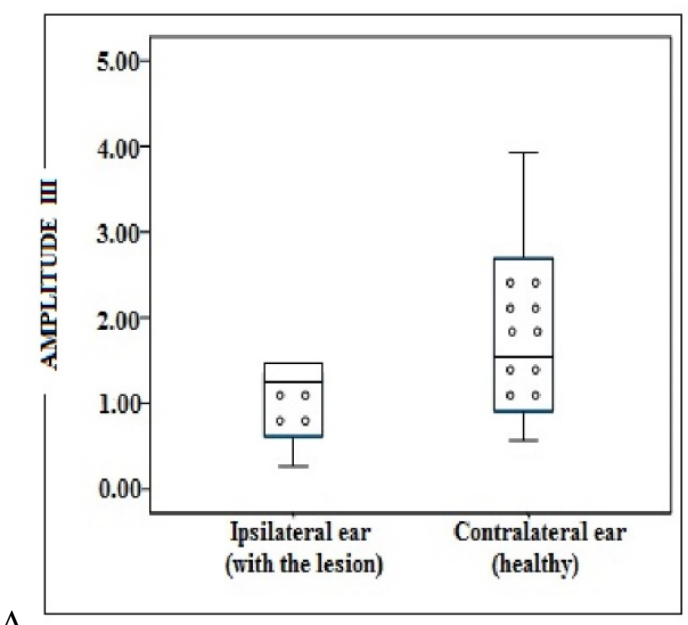

neither after binaural and contralateral ear (healthy) monaural stimulation, at intensity of stimulus of 90dB SPL.

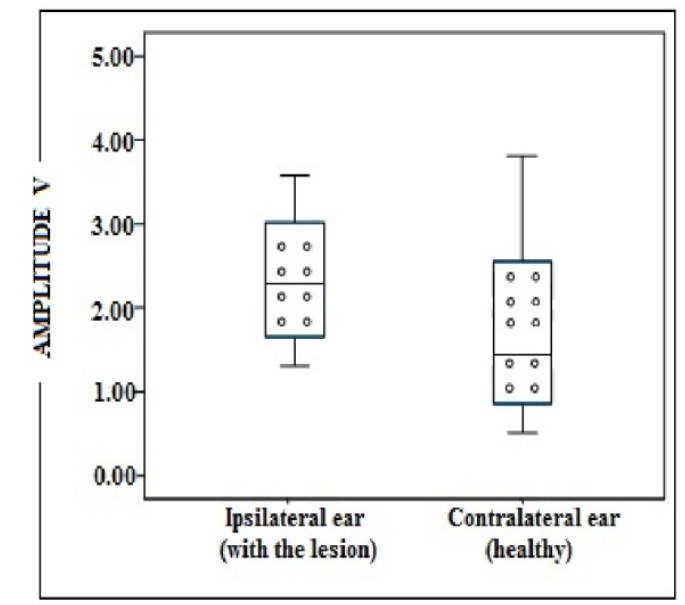

Figure 5. BAERs test performed on dogs with CVS. A. Amplitudes of waves III obtained by stimulation of the contralateral and the ipsilateral ear to the lesion. B. Values of the amplitudes of waves V obtained by stimulation of contralateral and ipsilateral ear to the lesion.

Comparing the values of intervals I-III, III-V, and $\mathrm{I}-\mathrm{V}$ recorded after the stimulation of the ipsilateral (affected) ear with those recorded after the stimulation of the contralateral (healthy) ear we did not notice significant differences $(\mathrm{P}>$ $0.05)$. No statistical differences were observed comparing the values of the intervals recorded after binaural and contralateral ear in monaural stimulation.

\section{DISCUSSIONS}

To the authors' knowledge, this is the first study describing BAERs test using surface electrodes in CVS in dogs.

Our recorded latencies, amplitudes and the values of the intervals are lower than those described by Cauzinille (1997), probably as a 
consequence of using surface electrodes (Jost et al. 1994; Musteață et al., 2013).

The success rate of identifying BAERs abnormalities in studies that use needle electrodes varies within very wide limits. Thus, Oliviera et al. (2012) in a study of 21 dogs with intracranial lesions found an abnormal BAERs only in 11 of them (52.38\%). Steiss et al. (1994) recorded $100 \%$ BAERs abnormalities in 14 dogs with confirmed central nervous system lesions. In our study, $70 \%$ of dogs with CVS showed an abnormal BAERs.

BAERs abnormalities consisted in the presence of waves III-V plateau, multiple discharges between waves III-V, absence of waves II-V and increased amplitudes of all waves, similar to those discribed in previous studies of brain diseases in dogs (Fischer and Obermaier, 1994; Steiss et al., 1994; Oliviera et al., 2012).

Lower values for the amplitudes of waves II, III and $\mathrm{V}$ were obtained from stimulation of the ipsilateral (affected) ear versus contralateral healthy ear. These results are similar to those reported in literature for intracranial lesions (Fischer et al., 1994; Steiss et al., 1994; Wilson, 2005; Wessmann et al., 2009; Colson et al., 2012).

When we compared the BAERs amplitudes and latencies recorded from the ipsilateral side of the lesion with those from the contralateral one, we obtained significant statistical differences only for amplitudes of all waves. This might suggest that in our cases the lesions influenced only the strength of potentials, not the speed of transmission of the information between the nuclei of the auditory pathway.

Five patients with CVS secondary to stroke were evaluated with BAERs. At the time of discharge, there were 2 deaths, 1 patient had a complete recovery, and 2 patients had an incomplete recovery.

In patients with stroke whose recovery was partial or total, BAERs abnormalities consisted only in a slight decrease of wave amplitude, statistically insignificant.

BAER testing in patients who died has highlighted a significant decrease for wave I amplitude in association with the absence of centrally generated potentials (II, III, and V) in $\operatorname{dog} 4$ and the presence of wave III-V plateau left ear and absence of waves II-V - right ear in dog 9. Those changes were previously reported only in humans with brain tumours (Legatt, 2005), as a consequence of total functional destruction of the brainstem auditory pathways associated with extensive lesions of the pons and mesencephalon and as well as in cerebral death.

In our cases, this change can be attributed to compression of the basilar or labyrinthine arteries, knowing that the inferior colliculus is perfused via the superior cerebellar and collicular arteries and therefore the integrity of the BAERs generators for wavers III, IV, and V is dependent on perfusion and occurs mainly in the basilar artery (Shimbo et al., 2003).

In patients with stroke, BAERs testing was more accurate, its changes were positively correlated with a clinical course.

In dogs with CVS caused by the tumor (dog 1 and 7 , both with cerebellar tumours), we observed a significant increase in monoauricular wave $\mathrm{V}$ latency $(5.08 \mu \mathrm{V})$ by stimulation of the ipsilateral (affected) ear versus contralateral healthy ear $(3.84 \mu \mathrm{V})$; these results indicate an impairment in the cranial portion of the brainstem wave, $\mathrm{V}$ is generated by inferior coliculul located in this region. Morphological analysis of the BAERs trace has highlighted presence of wave III-V plateau with a slight decrease in amplitude, and in dog 7 presence of multiple discharge bilaterally; probably as a result of tumor compression of the brain stem. Similar results were reported by Steiss et al. (1994) in dogs with brain stem, cerebellar and forebrain tumors in a study of 14 dogs with confirmed central nervous system lesions.

In the analysis of the BAERs traces in dogs with hydrocephalus ( $\operatorname{dog} 5$ and 8 ) no changes were observed in latency of the waves I, II, III, and V, when we compared their values between binaural and ipsilateral ear (affected) monaural stimulation, or after binaural and contralateral ear (healthy) monaural stimulation. An increase in the amplitudes were obtained in the case of III and $\mathrm{V}$ waves $(2.56 \mu \mathrm{V}$ and $3.15 \mu \mathrm{V})$ at ipsilateral ear (affected) monaural stimulation versus contralateral ear stimulation $(1.95 \mu \mathrm{V}$, 
respectively $2.51 \mu \mathrm{V})$. Increasing the amplitudes of the waves III and V reflects increased activity of the neurons' olivary complex located in the upper and lower coliculul activity probably due to injuries descending auditory pathways in the brain. Although there have been less studies in the veterinary medicine, Mulders and Robertson (2000a) have demonstrated in rats that descending auditory pathways from the auditory cortex to olivary complex they are extended to the nuclei olivocochlear terminating at the cochlea, and assume that the same thing happens to the dog, thus explaining BAERs anomalies recorded.

\section{CONCLUSIONS}

BAERs testing using surface electrodes in CVS were characterised by different types of morphological change of the waves in $70 \%$ of patients and decreased amplitudes without changes in latency waves. This suggests an impairment of strength, but not of the speed of transmission of information between the nuclei of the auditory pathways.

Acknowledgment - this paper was published under the frame of the European Social Fund, Human Resources Development Operational Programme 2007-2013, project no. POSDRU/159/1.5/S/132765.

\section{REFERENCES}

ARNOLD, S. The auditory brainstem response. In: ROESER, R; HOSFORD-DUNN, H.; VALENTE'S, M. (Eds.). Auditory: diagnosis, treatment strategies, and practice management. 2.ed. New York: Thieme-Medical Publoshers, 2007. p.426-442.

BESALTI, O.; SIRIN, Y.S.; PEKCAN, Z. The effect of chronic otitis externa-media on brainstem auditory evoked potentials in dogs. Acta Vet. Brno, v.77, p.615-624, 2008.

BIACABE, B.; CHEVALLIER, J.M.; AVAN, P. et al. Functional anatomy of auditory brainstem nuclei: application to the anatomical basis of brainstem auditory evoked potentials. Auris Nasus Larynx, v.28, p.85-94, 2001.

CAUZINILLE, L. La mesure des potentiels évoqués auditifs du tronc cérébral: une méthode objective pour tester l'audition. Point Vet., v.28, p.1065-1068, 1997.

COLSON, A.; FANUEL-BARRET, D.; JOSSIER, R. et al. Cushing reflex associated with a presumed global brainstem ischemia in a dog: diagnostic procedures and outcome. Rev. Med. Vet., v.163, p.174-177, 2012.

CVEJIC, D.; STEINBERG T.A.; KENT, M.S. et al. Unilateral and bilateral congenital sensorineural deafness in client-owned purebreed white cats. J. Vet. Intern. Med., v.23, p.392-395, 2009.

FISCHER, A.; OBERMAIER, G. Brainstem auditory-evoked potentials and neuropathologic correlates in 26 dogs with brain tumors. J. Vet. Intern. Med., v.8, p.363-369, 1994.

JOST, W.H.; ECKER, K.W.; SCHIMRIGK, K. Surface versus needle electrodes in determination of motor conduction time to the external anal sphincter. Int. J. Colorectal Dis., v.9, p.197-199, 1994.

KAWASAKI, Y.; INADA, S. Peaks of brainstem auditory evoked potentials in dogs. Vet. Res. Commun., v.18, p.383-396, 1994.

LEGATT, A.D. Brainstem auditory evoked potentials: methodology, interpretation and clinical applications, In: AMINOFF M.J. Electrodiagnosis in clinical neurology. Philadelphia: Elsevier, 2005. p.519-552.

LUTTGEN, P.J. Deafness in the dog and cat. Vet. Clin. N. Am., v.24, p.981-989, 1994.

MULDERS, W.H.; ROBERTSON D. Evidence for direct cortical innervation of medial olivocochlear neurones in rats. Hear. Res., v.144, p.65-72, 2000a.

MUSTEAȚĂ, M.; NECULAE, I.; ARMAȘU, M. et al. Brainstem auditory evoked potentials in healthy cats recorded with surface electrodes. Acta Vet. Brno, v.82, p.97-101, 2013.

OLIVIERA, M.; FUENTE, C.; PUMAROLA, M.; ANOR, S. Brainstem auditory evoked responses and magnetic resonance imaging findings in 21 dogs with intracranial lesions: a comparative study. In: EDUCATION SYMPOSIUM VETERINATY MEUROLOGY, 25., 2012, Ghent. Proceedings... Ghent: European College Veterinary Neurology, 2012. p.87. (Abstract). 
PALUMBO, M.I.P.; RESENDE, L.A.L.; MAYHEW, I.G.J.; BORGES, A.S. Brainstem auditory evoked potential testing in dalmatian dogs in Brazil. Arq. Bras. Med. Vet. Zootec., v.66, p.433-438, 2014

POMA, R.; CHAMBERS, H.; COSTA R.C. et al. MRI measurement of the canine auditory pathways and relationship with brainstem auditory evoked responses. Vet. Comp. Orthop. Traumatol., v.21, p.238-242, 2008.

SHIMBO, Y.; SAKATA, M.; HAYANO, M.; MORI, S. Topographical relationships between the brainstem auditory and somatosensory evoked potentials and the location of lesions in posterior fossa stroke. Neurol. Med. Chir., v.43, p.282-291, 2003.

STEISS, J.E.; COX, N.R.; HATHCOCK, J.T. Brain stem auditory-evoked response abnormalities in 14 dogs with confirmed central nervous system lesions. J. Vet. Int. Med., v.8, p.293-298, 1994.
VENKER-VAN H.A.J.; SIEMELINK, R.J.G.; SMOORENBURG, G.F. Auditory brainstem responses in the normal: auditory brainstem responses in the normal beagle, Vet. Q., v.11, p.129-137, 1989.

WEBB, A.A. Brainstem auditory evoked response (BAER) testing in animals. Can. Vet. J. v.50, p.313-318, 2009.

WESSMANN, A.; CHANDLER, K.E.; GAROSI, L.S. Ischaemic and haemorrhagic stroke in the dog. Vet. J., v.180, p.290-303, 2009.

WILSON, W.J.; MILLS P.C. Brainstem auditory-evoked response in dogs. Am. J. Vet. Res., v.66, p.2177-2187, 2005. 